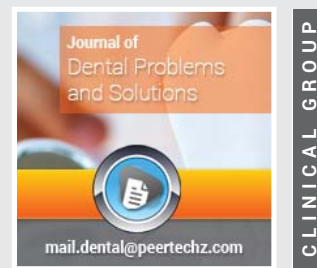

\section{A Winter ${ }^{1}$, J Kochel ${ }^{2}$, S Gerhardt- Szép ${ }^{3}$, D van $\mathrm{Rijt}^{4}$, S Kim ${ }^{5}$ and S Brandt ${ }^{5 *}$}

'Department of Prosthodontics, Dental School of the Medical Faculty, Julius Maximilian University, Würzburg, Germany

${ }^{2}$ Department of Orthodontics, Dental School of the Medical Faculty, Julius Maximilian University, Würzburg, Germany

${ }^{3}$ Department of Operative Dentistry, Center for Dentistry and Oral Medicine, Johann Wolfgang Goethe University, Frankfurt am Main, Germany ${ }^{4}$ Private Practice J. M. van Rijt, Altmühlstraße 30b, Bielefeld, Germany

${ }^{5}$ Department of Prosthodontics, Center for Dentistry and Oral Medicine, Johann Wolfgang Goethe

University, Frankfurt am Main, Germany

Received: 16 August, 2019

Accepted: 21 October, 2019

Published: 22 October, 2019

*Corresponding author: Silvia Brandt, D.D.S., Dr. Med. Dent, Department of Prosthodontics, Center for Dentistry and Oral Medicine, Johann Wolfgang Goethe University, Theodor-Stern-Kai 7, Building 29, 60596 Frankfurt am Main, Germany, Tel: +49 69630183617 ; E-mail: hajjaj@med.uni-frankfurt.de

Keywords: Interim dentures; Removable partial denture; Clasp-retained dentures; Success rate; Abutment teeth

https://www.peertechz.com

Check for updates

\section{Research Article}

\section{Oral-health implications and} maintenance needs of Removable Partial Dentures (RPDs) worn during pre-prosthetic treatment

\section{Introduction}

A growing number of effective measures for prophylaxis [13 ] is making a favorable impact on oral health at large and has been reducing the prevalence of caries and tooth loss. Despite these improvements, extensive dental rehabilitations continue to be required in daily clinical practice to compensate for losses of dental hard tissue and entire teeth. Any definitive restorative treatment will aim to provide high long-term stability, and any tooth-supported restoration, whether fixed or removable, will heavily depend on the quality of its abutment teeth. A key requirement to improve the prognosis of these teeth is that any pretreatment steps that may be needed to establish intact oral conditions are completed before the definitive stage of prosthetic treatment.

The duration of such pretreatment will vary with the extensiveness of the measures involved. While single treatment sessions will largely suffice to complete any operative pretreatment steps, the presence of periodontal disease will call for a systematic therapeutic regimen whose success, and hence the quality of any periodontally involved teeth to be used as abutments, can only be evaluated after a healing period of 3-4 months [4]. Several months of healing may also be required for endodontic pretreatment of apical lesions [5]. Then there are those situations where hopeless teeth need to be extracted, often followed by dental implant surgery to strategically maximize the number of abutments, which may additionally involve a procedure of bone augmentation, thus extending the period of implant osseointegration and delaying the time of prosthetic rehabilitation even further [6]. Last but not least, several months of pretreatment may be required due to functional conditions [7].

Hence the treatment steps preceding the actual prosthetic therapy may take anywhere from a few weeks to several 
months, depending on the number and severity of the preexisting oral-health conditions. The clinician in charge of the overall treatment may find it difficult to implement an adequate provisional restoration for this transitional period. Providing the patient with an esthetic and functional temporary replacement of his or her lost teeth is particularly important in residually dentate situations, which is where the indication for a removable partial denture (RPD) routinely comes in.

An interim RPD offers a number of advantages. It can restore function and esthetics, preserve or restore an appropriate intermaxillary relation $[8,9]$, allow for good hygiene and expandability, and be fabricated at a cost affordable to a large number of patients [10]. On the downside, an interim RPD will feature clasps that may be visible enough to compromise its esthetics. Also, the fact that the abutment teeth will be covered by the denture base and clasp structures on a continuous basis carries a risk of periodontal and carious destruction if the patient's oral hygiene is less than ideal [11].

Considering these shortcomings, there is a need to critically review the practice of utilizing interim RPDs of this type, keeping in mind that the quality of the abutment teeth should actually be improving, rather than deteriorating, below a temporary prosthesis that is worn prior to the definitive prosthetic stage of treatment. The question arises whether, and for how long, an interim RPD can truly be a considered a useful transitional prosthesis in pre-prosthetic situations. To address this question, we designed a retrospective study evaluating the oral-health implications of interim RPDs on the lookout for potential associations that may contribute to improving patient care.

\section{Materials and Methods}

We reevaluated clasp-retained interim RPDs that had been fabricated and inserted at our Department of Prosthodontics (Johann Wolfgang Goethe University, Frankfurt, Germany) during the period 2001 to 2014. All these treatments had been performed in undergraduate courses under faculty supervision and in the resident postgraduate program. Approval for the study was obtained from the institutional review board (IRB) of Johann Wolfgang Goethe University Medical School.

Our inclusion criteria were met by any RPDs that were covered by documentation of the initial (periodontal, operative, prosthodontic) dental situation and had been fabricated and inserted in accordance with the treatment standards in place at our Dental School. Any cases that did not meet required documentation standards or were associated with documented histories of malignancy or of drug/alcohol abuse were excluded. Any events of resin or clasp fracture and abutment or retention loss were defined as RPD failure.

Events related to abutment teeth were analyzed, all data being captured from patient records pertaining to diagnostic findings, treatment progress, Kennedy classes (I-IV), and maintenance requirements. Statistical calculations were performed using IBM SPSS Statistics 24 (SPSS Inc. an IBM
Company, Chicago, IL, USA). A Kolmogorov-Smirnov test to verify the presence of a normal data distribution was used first, and subsequently we proceeded to analyze quantitative parameters using chi-square, Kruskal-Wallis and Fisher's exact tests. Differences $\mathrm{p} \leq 0.05$ were considered statistically significant.

\section{Results}

\section{Descriptive data}

A total of 575 clasp-retained interim RPDs met our inclusion criteria. This resultant sample consisted of 302 maxillary and 273 mandibular dentures and covered a mean observation period of $31.21 \pm 22.02(3-158)$ months. It included 575 patients ( 248 women, $327 \mathrm{men}$ ) who were $62.0 \pm 11.1$ years old at the time of inserting the RPDs.

\section{Success rate}

Figure 1 illustrates the most common causes of failure. The total success rate of all interim RPDs was $60.7 \%$ based on the above-mentioned observation period. Broken down by jaws, the rate was $56.0 \%$ for maxillary and $65.9 \%$ for mandibular RPDs. The mandibular PRDs performed significantly better than the maxillary PRDs (chi-square test; p=0.014), and compliance with the periodic recalls was associated with a significantly higher success rate than noncompsliance (chi-square test; $\mathrm{p}=0.023$ ). Table 1 lists the Kennedy classes involved in the sample, but no statistically significant association was seen between the RPD success rates and Kennedy classes (KruskalWallis test: $\mathrm{p}=0.545$ ).

\section{Oral-health implications}

No changes in mobility grades were observed in $70.1 \%$, deteriorations in $24.9 \%$, and improvements in $5 \%$ of RPDs. Note that single-arm clasps were used to retain the RPDs, and

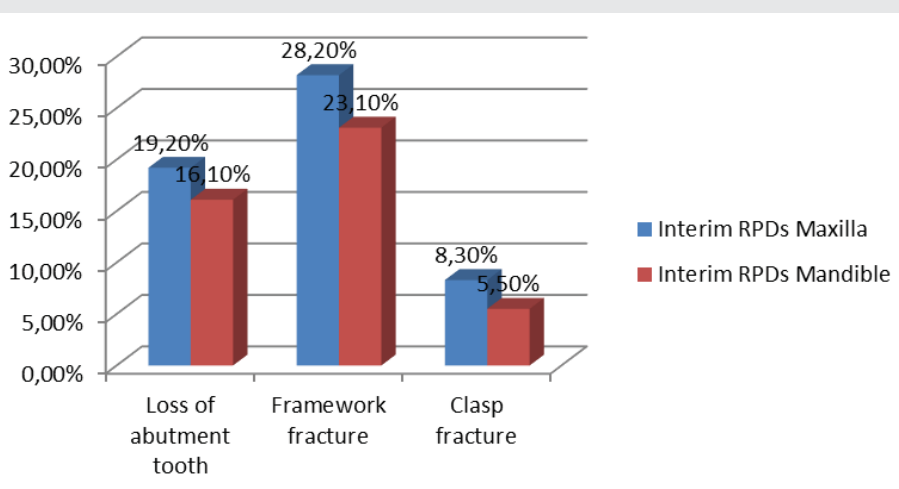

Figure 1: Causes of denture failure.

Table 1: Distribution of Kennedy classes.

\begin{tabular}{|c|c|}
\hline Kennedy class & Total (n) \\
\hline I & 308 \\
\hline II & 149 \\
\hline III & 109 \\
\hline IV & 9 \\
\hline
\end{tabular}


Figure 2 illustrates the relative occurrences of carious decay on the various types of abutment teeth. The incidence of caries under single-arm clasps was significant in both jaws (Fisher's exact/chi-square test: <0.05). Actual loss of abutment teeth under singlearm clasps affected $11.0 \%$ of lower molars, $12.6 \%$ of lower premolars, $12.2 \%$ of lower canines, $15.4 \%$ of lower incisors, $10.9 \%$ of upper molars, $13.0 \%$ of upper premolars, $9.7 \%$ of upper canines, and $11.3 \%$ of upper incisors. This incidence of tooth loss, too, was statistically significant at all sites (Fisher's exact/Pearson's chi-square test: <0.05).

\section{Maintenance and repairs}

Relief of pressure sores was the most frequent requirement for maintenance, affecting 270 (47\%) of RPDs during the first month of intraoral service. Resin fractures occurred in 147 (25.6\%) of RPDs. Significantly fewer fractures were diagnosed with RPDs featuring a reinforcement brace than in those lacking this feature (chi-square test: $\mathrm{p}=0.002)$. Clasp fractures occurred in $43(7.5 \%)$ of RPDs, and 77 of the maxillary (=25,5\%) and 57 of the mandibular $(=20,9 \%)$ dentures needed relining. A total of 310 (54\%) dentures needed repair. Table 2 lists repairfree RPDs at different points of time.

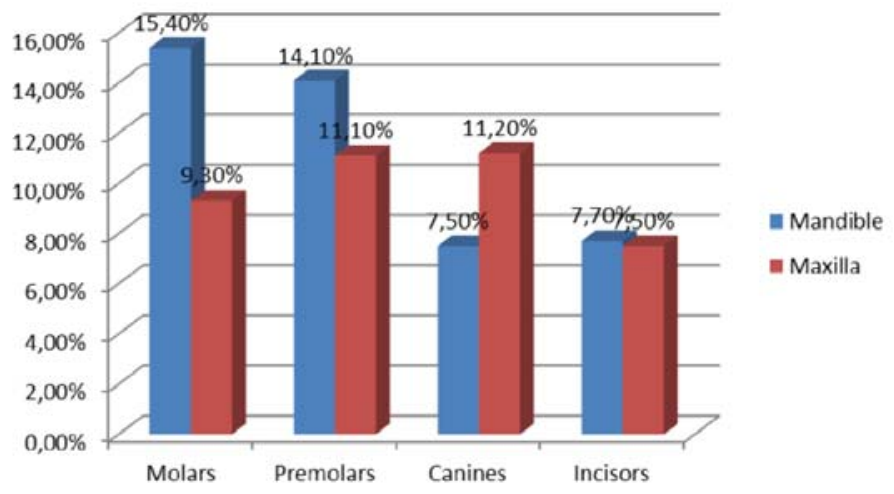

Figure 2: Incidence of caries on abutment teeth.

Table 2: Mean percentages of RPDs which had not required repair by different points in time.

\begin{tabular}{|c|c|}
\hline \multicolumn{2}{|c|}{ Time from Repair-free RPDs insertion (percent \pm SD) } \\
\hline 3 months & $84.0 \pm 1.5$ \\
\hline 4 months & $79.5 \pm 1.7$ \\
\hline 6 months & $72.5 \pm 1.9$ \\
\hline 9 months & $66.9 \pm 2.0$ \\
\hline 12 months & $61.3 \pm 2.0$ \\
\hline 24 months & $48.2 \pm 2.3$ \\
\hline 36 months & $41.2 \pm 2.5$ \\
\hline 48 months & $36.1 \pm 2.9$ \\
\hline 60 months & $32.8 \pm 3.2$ \\
\hline
\end{tabular}

\section{Discussion}

The 575 interim RPDs herein reported may be considered a large sample and the followup of $31.21 \pm 22.02$ months to be a long mean observation period. Given a total success rate of $60.7 \%$ over this period, the mandibular RPDs performed significantly better than the maxillary ones $(65.9 \%$ versus $56,0 \%)$. This finding is consistent with a higher survival rate of lower than upper clasp-retained dentures reported by Rehmann et al. [12]. Since the majority of the 310 repairs in our study were due to clasp $(n=143)$ or resin $(n=43)$ fractures, these two events types contributed greatly to the success rate here reported.

Considering typical regimens of operative and periodontal pretreatment that may be required before the definitive prosthetic stage, a 3-month timeframe of wearing an interim prosthesis would appear realistic. Given that $84 \pm 1.5 \%$ of interim RPDs in our study did not require repair within the first 3 months, their use may be recommended in these situations. Yet a 3-month period does not account for many situations (e.g. those involving more extensive needs for pretreatment and/or implant placement) requiring an interim prosthesis for longer periods, and our data do indicate that the rate of repairfree RPDs was down to $72.5 \pm 1.9 \%$ and $66.9 \pm 2 \%$ after 6 and 9 months, respectively. Thus interim RPDs pale against definitive restorations given this finding that their risk of failure will steadily increase month by month due to their inexpensive fabrication.

In addition, clasp retention is per se more liable to cause failure of the denture than other retention mechanisms such as telescopes [13]. Gad et al. [14] have also reported on denture fracture as a common cause of failure that involves high maintenance needs. Fracture resistance can be improved by repairing the denture base with an appropriate resin [15]. While light-curing resins may offer a quick-and-cheap fix, they favor adhesion of Candida albicans and thus increase the risk of denture stomatitis [16], which can be reduced by using additives (e.g. zirconia nanoparticles or thymoquinone) and by conducting the repair professionally $[14,17]$. Denture sores were another major source of maintenance needs in the present investigation. Studies have shown that interim dentures are associated with increased mucosal pain and, accordingly, with reduced chewing ability $[18,19]$. An effort should therefore be made to achieve secure and pain-free seating of the denture so that good masticatory function will be ensured.

Another point of investigation concerned the impact of interim RPDs on the abutment teeth. We observed no changes in tooth mobility in $70.1 \%$ and increases in $24.9 \%$ of RPDs. The latter cases of deterioration could have been due either to plaque-induced periodontal destruction or to mechanical loading by the clasps. Despite reports on a direct impact of denture design on periodontal health, our finding that abutment teeth were significantly associated with carious lesions and tooth loss would rather argue in favor of plaque accumulation as the cause of increasing mobility [20,21]. Our rates of tooth loss and carious lesions on abutment teeth are consistent with previous reports [22]. Plaque accumulation as the main causative factor would also explain our finding that patient compliance with periodic recalls was associated with a higher success rate of interim RPDs, considering that oral 
hygiene was continuously optimized throughout these visits. Last but not least, the facts that tooth mobility remained unchanged in the majority of cases, and was even found to improve in some, suggests that compromised abutment teeth cannot be generalized as an inevitable outcome of interim RPDs.

\section{Conclusions}

Based on the results presented in his article, an interim $\mathrm{RPD}$ can be recommended for the duration of any pretreatment regimens that may be required before the definitive prosthetic stage. However, care needs to be exercised to limit the duration of such pretreatment and intraoral service of the denture. Our results for repair needs within the first 3 to 6 months of insertion suggest that an interim RPD may be usefully worn during this timeframe. By 9 months of insertion, one-third of the interim RPDs had already been repaired. We therefore recommend avoiding their use beyond that time.

Whenever a need for repair arises, an appropriate material should be selected to avoid the development of denture stomatitis. Periodic checks for pressure sores and relining needs are required to ensure proper seating of the denture. To minimize periodontal and carious lesions, advantage should be taken of the favorable effect of periodic recalls demonstrated by the present study. Within the limitations of the abovementioned risks and intraoral service durations, an interim RPD does constitute an adequate transitional solution for patients undergoing a variety of pre-prosthetic regimens of pretreatment.

\section{References}

1. Al-Maliky MA, Frentzen M, Meister J (2019) Laser-assisted prevention of enamel caries: A 10-year review of the literature. Lasers Med Sci. Link: https://bit.ly/2KxPbUs

2. Colvara BC, Faustino-Silva DD, Meyer E, Hugo FN, Hilgert JB, et al. (2018) Motivational interviewing in preventing early childhood caries in primary healthcare: a community-based randomized cluster trial. J Pediatr 201: 190195. Link: https://bit.ly/2H6Wgcq

3. Alm A (2008) On dental caries and caries-related factors in children and teenagers. Swed Dent J Suppl 7-63. Link: https://bit.ly/2Z1 Hp9q

4. Eberhard J, Jepsen S, Jervoe-Storm PM, Needleman I, Worthington HV (2015) Full-mouth treatment modalities (within 24 hours) for chronic periodontitis in adults. Cochrane Database Syst Rev CD004622. Link: https://bit.ly/306Yikg

5. Ng YL, Mann V, Gulabivala K (2011) A prospective study of the factors affecting outcomes of nonsurgical root canal treatment: part 1: periapical health. Int Endod J 44: 583-609. Link: https://bit.ly/2H7yMUz

6. Zafiropoulos GG, Parashis A, Abdullah T, Sotiropoulos E, John G (2018) Comprehensive Treatment of severe periodontal and periimplant bone destruction caused by iatrogenic factors. Case Rep Dent 2018: 7174608 . Link: https://bit.ly/2TuNzOd
7. Mays KA (2003) Reestablishing occlusal vertical dimension using a diagnostic treatment prosthesis in the edentulous patient: a clinical report. $J$ Prosthodont 12: 30-36. Link: https://bit.ly/2MgQYiH

8. Priest G (2006) Esthetic potential of single-implant provisional restorations: selection criteria of available alternatives. J Esthet Restor Dent 18: 326-338 Link: https://bit.ly/2KzfvOh

9. Siadat $\mathrm{H}$, Alikhasi $\mathrm{M}$, Beyabanaki E (2017) Interim prosthesis options for dental implants. J Prosthodont 26: 331-338. Link: https://bit.ly/33BnBwQ

10. Santosa RE (2007) Provisional restoration options in implant dentistry. Aust Dent J 52: 234-242. Link: https://bit.ly/2TxrluG

11. Zlataric DK, Celebic A, Valentic-Peruzovic M (2002) The effect of removable partial dentures on periodontal health of abutment and non-abutment teeth J Periodontol 73: 137-144. Link: https://bit.ly/2H7U7Ny

12. Rehmann P, Orbach K, Ferger P, Wostmann B (2013) Treatment outcomes with removable partial dentures: a retrospective analysis. Int $\mathrm{J}$ Prosthodont 26: 147-150. Link: https://bit.ly/2H7bVbB

13. Wagner B, Kern M (2000) Clinical evaluation of removable partial dentures 10 years after insertion: success rates, hygienic problems, and technical failures. Clin Oral Investig 4: 74-80. Link: https://bit.ly/2YM9mXr

14. Gad MM, Al-Thobity AM, Shahin SY, Alsaqer BT, Ali AA (2017) Inhibitory effect of zirconium oxide nanoparticles on Candida albicans adhesion to repaired polymethyl methacrylate denture bases and interim removable prostheses: a new approach for denture stomatitis prevention. Int $\mathrm{J}$ Nanomedicine 12 54095419. Link: https://bit.ly/2KxsBv9

15. Faot F, da Silva WJ, da Rosa RS, Del Bel Cury AA, Garcia RC (2009) Strength of denture base resins repaired with auto- and visible light-polymerized materials. J Prosthodont 18: 496-502. Link: https://bit.ly/2Z40t99

16. Sahin C, Ergin A, Ayyildiz S, Uzun G (2012) Evaluation of flexural strength and Candida albicans adhesion of an acrylic resin repaired with 4 different resin materials. Clin Dent Res 36: 10-14. Link: https://bit.ly/2KyNm9B

17. Al-Thobity AM, Al-Khalifa KS, Gad MM, Al-Hariri M, Ali AA, et al. (2017) In vitro evaluation of the inhibitory activity of thymoquinone in combatting Candida albicans in denture stomatitis prevention. Int J Environ Res Public Health 14 Link: https://bit.ly/2OR5DmH

18. Fueki K, Yoshida-Kohno E, Inamochi Y, Wakabayashi N (2019) The association between mucosal pain and subjective masticatory function in patients with partial removable dental prostheses. J Oral Rehabil Link: https://bit.ly/2TyY4zL

19. Kumagai H, Fueki K, Yoshida-Kohno E, Wakabayashi N (2016) Factors associated with mucosal pain in patients with partial removable dental prostheses. J Oral Rehabil 43: 683-691. Link: https://bit.ly/2KAPOwt

20. Behr M, Zeman F, Passauer T (2012) Clinical performance of cast claspretained removable partial dentures: a retrospective study. Int J Prosthodont 25: 138144. Link: https://bit.ly/303AQ7w

21. Petridis $\mathrm{H}$, Hempton TJ (2001) Periodontal considerations in removable partial denture treatment: a review of the literature. Int J Prosthodont 14 164-172. Link: https://bit.ly/2Z4gw8P

22. Moldovan O, Rudolph H, Luthardt RG (2018) Biological complications of removable dental prostheses in the moderately reduced dentition a systematic literature review. Clin Oral Investig 22: 2439-2461. Link: https://bit.ly/2yVODTx

Copyright: @ 2019 Winter A, et al. This is an open-access article distributed under the terms of the Creative Commons Attribution License, which permits unrestricted use distribution, and reproduction in any medium, provided the original author and source are credited. 